\title{
Organização e dinâmica do Conselho Municipal de Segurança Alimentar e Nutricional de São Paulo: implicações para a sua atuação na construção da política municipal de Segurança Alimentar e Nutricional
}

\author{
Organization and dynamics of Conselho Municipal de \\ Segurança Alimentar e Nutricional de São Paulo: \\ implications of their participation on the creation \\ of a municipal food and nutrition security policy
}

Nayara Côrtes ROCHA ${ }^{1}$ Natália Gebrim DORIA² Juliana Marques BOIA ${ }^{2}$ Cláudia Maria BÓGUS²

RE S U M O

\section{Objetivo}

Analisar o funcionamento, a organização e a participação política internas do Conselho Municipal de Segurança Alimentar e Nutricional de São Paulo e quais as possíveis implicações decorrentes na sua atuação no processo de construção de uma política municipal de segurança alimentar e nutricional.

\section{Métodos}

O estudo de abordagem qualitativa constituiu-se em três etapas: análise documental de atas; observação de reuniões e realização de entrevistas semi-estruturadas com conselheiros, considerados informantes-chave. O eixo de análise foi a participação política do Conselho considerando seus aspectos internos, como composição, dinâmica de funcionamento e participação política de seus membros e a relação destes tópicos com a atuação do Conselho na definição e elaboração de uma política municipal de segurança alimentar e nutricional.

\section{Resultados}

O perfil "intelectualizado" dos conselheiros não é representativo da maioria da população e facilita o afastamento de questões concretas nas discussões do conselho; a rígida dinâmica interna e a assimetria entre seus membros

\footnotetext{
1 Nutricionista. São Paulo, SP, Brasil.

2 Universidade de São Paulo, Faculdade de Saúde Pública, Curso de Nutrição. Av. Dr. Arnaldo, 715, 01246-904, São Paulo, SP, Brasil. Correspondência para/Correspondence to: CM BÓGUS.E-mail: <claudiab@usp.br>.
} 
134 | NC ROCHA et al.

dificultam, de forma geral, a participação ativa dos conselheiros e, especificamente, as discussões sobre políticas de segurança alimentar e nutricional. Os denominados "conselheiros-militantes" apresentam participação diferenciada, mais crítica, com maior domínio sobre o tema e suas discussões.

\section{Conclusão}

O perfil dos conselheiros, a organização interna do Conselho, além da complexidade do tema e sua pequena inserção na sociedade, fazem que o conselho atue distante das demandas sociais e de forma incipiente com relação às políticas de segurança alimentar e nutricional no município.

Termos de indexação: Conselhos. Participação. Segurança alimentar e nutricional.

\section{A B S T R A C T}

\section{Objective}

This study analyzed the internal functioning, organization and political participation of the local food and nutrition security council and possible implications of their participation on the creation of a municipal food and nutrition security policy in the city of São Paulo.

\section{Methods}

This qualitative study was done in three stages: document analysis; observation of meetings and semi-structured interviews with board members considered key informants. The axis of analysis was the political participation of the council, considering its internal aspects, like board members, operating dynamics of political participation of its members and the relationship between these topics and the council's actions for the definition and creation of a food and nutrition security policy.

\section{Results}

The intellectual profile of the board members does not represent the majority of the population, thereby facilitating the omission of actual issues in council discussions. Its strict internal dynamics and the asymmetry of its members generally prevent the active participation of board members and, specifically, discussions about a food and nutrition security policy. The so-called "militant members" have a differentiated, more aggressive participation, with greater mastery of the subject and its topics.

\section{Conclusion}

The board member profiles, internal organization of the council, complexity of the subject and its low insertion in the society distance the council from social needs and lead them to act incipiently with regard to the municipal policies of food and nutrition security.

Indexing terms: Councils. Participation. Food security.

\section{N T R O D U ÇÃ O}

Estudos sobre instâncias democráticas participativas, com ênfase nos Conselhos de Saúde devido ao seu pioneirismo, vêm apontando as dificuldades comuns entre conselhos de diferentes áreas e municípios, tais como baixa representatividade de conselheiros, burocratização, assimetria entre membros, debates superficiais, esvaziamento político, despreparo de conseIheiros, manipulação de pautas e discussões pelos gestores, falta de publicização do Conselho e de suas pautas, baixa participação da população, pequena relevância na formulação de política pública, dentre outros ${ }^{1-4}$.
No caso dos Conselhos de Segurança Alimentar e Nutricional, além desses problemas, desafios específicos da área precisam ser analisados e entendidos, como a pouca inserção da discussão sobre Segurança Alimentar e Nutricional (SAN) na sociedade e a dificuldade de articulação dos diversos setores ligados a ela.

No Brasil, a temática de SAN é vinculada à mobilização social e às lutas pela democratização da sociedade, desde o início de sua história, na década de 1980, quando movimentos lutavam não apenas por políticas públicas contra a fome e pela garantia da SAN, como pelo direito de acompanhar e participar da construção dessas 
políticas. Assim, lutaram também pela constituição do Conselho Nacional de Segurança Alimentar e Nutricional (CONSEA), criado em 1993 e extinto em $1995^{5}$.

Desativado por quase dez anos, o CONSEA retomou suas atividades em 2003 e ocupa, desde então, importante papel na mobilização e na construção de políticas públicas de SAN, alcançando conquistas importantes. Dentre elas, destacam-se a criação da Lei Orgânica de Segurança Alimentar e Nutricional (LOSAN), mudanças nas diretrizes do Programa Nacional de Alimentação Escolar (PNAE) e a inclusão do Direito Humano à Alimentação Adequada (DHAA) na Constituição Federal.

A LOSAN, que propôs Sistema de Segurança Alimentar e Nutricional (SISAN) essencialmente intersetorial, que deve contemplar ações desde a produção sustentável de alimentos, passando por políticas que ampliem o acesso permanente e ininterrupto da população a esses alimentos, estimulando práticas alimentares saudáveis, por meio de políticas econômica, social e ambientalmente sustentáveis e que garantam adequação nutricional, sanitária e cultural da alimentação para todos. O Sistema Nacional de Segurança Alimentar e Nutricional, por sua vez, deve ser um sistema por meio do qual o poder público, com a participação da sociedade civil organizada, formulará e implantará políticas e ações com vistas a assegurar o DHAA. Tem entre seus princípios a participação social na formulação, execução, acompanhamento, monitoramento e controle dessas políticas em todas as esferas governo, o que torna fundamental o papel dos Conselhos de Segurança Alimentar e Nutricional nas diferentes instâncias ${ }^{6}$.

O Conselho Municipal de Segurança Alimentar e Nutricional de São Paulo (COMUSANSP) foi instituído em 2003, sendo seu atual regimento interno datado de 2008. À época de sua criação, era vinculado à extinta Secretaria Municipal de Abastecimento e, atualmente, vincula-se à Municipal de Coordenação das Subprefeituras, por meio da Supervisão Geral de Abastecimento.
Atualmente, o Conselho é formado por 45 membros titulares e igual número de suplentes, com 15 representantes governamentais e 30 da sociedade civil organizada, sendo desses representantes de trabalhadores de áreas afins ao setor de alimentos. Seu regimento interno define a composição da representação por "subsegmentos" dentro dos segmentos governo e sociedade civil (Quadro 1)7. Os representantes dos órgãos governamentais são indicados por suas respectivas pastas, enquanto os representantes da sociedade civil devem ser eleitos nas Conferências Municipais de Segurança Alimentar e Nutricional. O tempo de mandato dos conselheiros é de 36 meses.

Observando-se o Quadro 1, verifica-se que os subsegmentos presentes na sociedade civil correspondem a movimentos sociais, entidades sindicais patronais e de trabalhadores, conselhos profissionais, instituições de ensino e entidades de portadores de doenças relacionadas à alimentação e nutrição. Com tal tipo de composição, porém, não é possível estabelecer uma relação entre as entidades representadas e os setores de produção, comercialização e consumo de alimentos.

Considerando-se a potencialidade dos Conselhos Gestores de Políticas Públicas na elaboração de políticas públicas mais democráticas e eficazes, e considerando-se ainda que a própria construção coletiva da LOSAN seria um impulso para a organização do SISAN em cada região do país sob os mesmos marcos, desenhou-se este estudo com o objetivo de conhecer a organização, a dinâmica e o funcionamento interno do COMUSAN e quais as possíveis implicações, decorrentes de sua atuação, no processo de construção de uma política municipal de segurança alimentar e nutricional.

\section{MÉTODOS}

O presente estudo, de caráter qualitativo, foi realizado entre novembro de 2008 e outubro de 2009 e constituiu-se em três etapas: análise documental, por meio da leitura das atas das 
136 | NC ROCHA et al.

Quadro 1. Composição da representação por subsegmentos do COMUSAN.

Segmento governamental
Secretaria Municipal de Coordenação das Subprefeituras (SMSP),
sendo um por região (Norte, Sul, Leste I, Leste II e Oeste/Centro)
(5 representantes)
Supervisão Geral de Abastecimento (ABAST), da Secretaria Mu-
nicipal de Coordenação das Subprefeituras (SMSP) (1 represen-
tante)
Secretaria Municipal da Saúde (SMS) (1 representante)
Secretaria Municipal de Educação (SME) (1 representante)
Secretaria Municipal de Assistência e Desenvolvimento Social
(SMADS) (1 representante)
Secretaria Municipal do Verde e do Meio Ambiente (SVMA) (1
representante)
Secretaria Estadual da Saúde (1 representante)
Sesquisa, (2 representantes, sendo 1 do Centro Tecnológico Paula
tante)
Instituições públicas estaduais de ensino técnico/superior e de
Paulo (CONSEA-SP) (1 representante)

Segmento sociedade civil

Movimentos populares, sociais e comunitários, com interface nas questões de segurança alimentar (5 representantes)

Entidades sindicais e associações gerais patronais e de entidades sindicais e associações patronais da área (5 representantes)

Instituições de ensino privado técnico/superior e de pesquisa (5 representantes)

Entidades de portadores de doenças relacionadas à alimentação e nutrição (2 representantes)

Entidades de pessoas com deficiências (1 representante)

Entidades prestadoras de serviços (2 representantes)

Entidades sindicais de trabalhadores de áreas afins à segurança alimentar e nutricional (3 representantes)

Associações de trabalhadores de áreas afins à segurança alimentar e nutricional (3 representantes)

Conselhos regulamentadores de profissões, ligados à área de segurança alimentar e nutricional (3 representantes)

Entidades que congreguem profissionais com atuação relevante em questões de sustentabilidade ambiental (1 representante)

Fonte: Prefeitura Municipal de São Paulo7.

reuniões de fevereiro de 2006 a junho de 2009; observação de reuniões; e realização de entrevistas semiestruturadas. Nestas últimas, contemplou-se a identificação do entrevistado e do órgão e/ou entidade que ele representa, bem como a sua percepção sobre a organização do COMUSAN, seu funcionamento e suas possibilidades de intervenção na elaboração de uma política municipal de segurança alimentar e nutricional, a partir das proposições da LOSAN.

Foram realizadas 17 entrevistas, com oito dos representantes governamentais e nove representantes da sociedade civil, sendo apenas um deles suplente, por se tratar de membro-chave da Comissão Executiva do Conselho. A seleção de conselheiros dentro dos subsegmentos foi feita em função de sua frequência e participação nas reuniões, na tentativa de garantir a fidedignidade e atualidade das informações prestadas. A distribuição dos entrevistados por segmento e subsegmentos encontra-se no Quadro 2.
Os dados coletados por meio das entrevistas individuais foram compilados, agrupados e categorizados, considerando-se separadamente cada um dos segmentos.

O artigo foca sua análise na estrutura, funcionamento, composição e organização do Conselho e indica possíveis repercussões dessa dinâmica para uma efetiva deliberação sobre a política de segurança alimentar e nutricional do município.

A pesquisa foi aprovada pelo Comitê de Ética da Faculdade de Saúde Pública (OF. COEP/237/09).

\section{RESULTADOS}

As entidades da sociedade civil são diversas, representando diferentes grupos sociais. Apesar disso, referem objetivos comuns: capacitação profissional e mobilização social, o que propicia a realização de ações conjuntas, relatado pela maior 
Quadro 2. Número de representantes e de entrevistados em cada subsegmento do COMUSAN.

\begin{tabular}{|c|c|c|c|}
\hline Segmento Governamental & Entrevistados (n) & Segmento Sociedade Civil & Entrevistados (n) \\
\hline $\begin{array}{l}\text { Secretaria Municipal de Coordenação das } \\
\text { Subprefeituras (SMSP), sendo um por re- } \\
\text { gião (Norte, Sul, Leste I, Leste II e Oeste/ } \\
\text { Centro) (5 representantes) }\end{array}$ & 4 entrevistados & $\begin{array}{l}\text { Movimentos populares, sociais e comunitá- } \\
\text { rios, com interface nas questões de Segu- } \\
\text { rança Alimentar e Nutricional ( } 5 \text { represen- } \\
\text { tantes) }\end{array}$ & 1 entrevistado \\
\hline $\begin{array}{l}\text { Supervisão Geral de Abastecimento - Se- } \\
\text { cretaria Municipal de Coordenação das } \\
\text { Subprefeituras (1 representante) }\end{array}$ & 1 entrevistado & $\begin{array}{l}\text { Entidades sindicais e associações gerais pa- } \\
\text { tronais e de entidades sindicais e associa- } \\
\text { ções patronais da área ( } 5 \text { representantes) }\end{array}$ & 2 entrevistados \\
\hline $\begin{array}{l}\text { Secretaria Municipal da Saúde (1 repre- } \\
\text { sentante) }\end{array}$ & Nenhum entrevistado & $\begin{array}{l}\text { Instituições de ensino privado técnico/supe- } \\
\text { rior e de pesquisa ( } 5 \text { representantes) }\end{array}$ & 1 entrevistado \\
\hline $\begin{array}{l}\text { Secretaria Municipal de Educação (1 re- } \\
\text { presentante) }\end{array}$ & Nenhum entrevistado & $\begin{array}{l}\text { Entidades de portadores de doenças rela- } \\
\text { cionadas à alimentação e nutrição ( } 2 \text { repre- } \\
\text { sentantes) }\end{array}$ & 1 entrevistado \\
\hline $\begin{array}{l}\text { Secretaria Municipal de Assistência e De- } \\
\text { senvolvimento Social (1 representante) }\end{array}$ & Nenhum entrevistado & $\begin{array}{l}\text { Entidades de pessoas com deficiências ( } 1 \text { re- } \\
\text { presentante) }\end{array}$ & Nenhum entrevistado \\
\hline $\begin{array}{l}\text { Secretaria Municipal do Verde e do Meio } \\
\text { Ambiente (1 representante) }\end{array}$ & 1 entrevistado & $\begin{array}{l}\text { Entidades prestadoras de serviços ( } 2 \text { repre- } \\
\text { sentantes) }\end{array}$ & 2 entrevistados \\
\hline $\begin{array}{l}\text { Secretaria Estadual da Saúde (1 represen- } \\
\text { tante) }\end{array}$ & 1 entrevistado & $\begin{array}{l}\text { Entidades sindicais de trabalhadores de áre- } \\
\text { as afins à segurança alimentar e nutricional } \\
\text { (3 representantes) }\end{array}$ & 1 entrevistado \\
\hline $\begin{array}{l}\text { Secretaria Estadual da Agricultura e Abas- } \\
\text { tecimento ( } 1 \text { representante) }\end{array}$ & Nenhum entrevistado & $\begin{array}{l}\text { Associações de trabalhadores de áreas afins } \\
\text { à segurança alimentar e nutricional ( } 3 \text { re- } \\
\text { presentantes) }\end{array}$ & 1 entrevistado \\
\hline $\begin{array}{l}\text { Instituições públicas estaduais de ensino } \\
\text { técnico/superior e de pesquisa, ( } 2 \text { repre- } \\
\text { sentantes, sendo } 1 \text { do Centro Tecnológico } \\
\text { Paula Souza (CEETC) e } 1 \text { da Universidade } \\
\text { de São Paulo (USP) }\end{array}$ & 1 entrevistado & $\begin{array}{l}\text { Conselhos regulamentadores de profissões, } \\
\text { ligados à área de SAN (3 representantes) }\end{array}$ & Nenhum entrevistado \\
\hline $\begin{array}{l}\text { Conselho Estadual de Segurança Alimen- } \\
\text { tar e Nutricional de São Paulo (CONSEA- } \\
\text { SP) (1 representante) }\end{array}$ & Nenhum entrevistado & $\begin{array}{l}\text { Entidades que congreguem profissionais } \\
\text { com atuação relevante em questões de } \\
\text { sustentabilidade ambiental ( } 1 \text { representan- } \\
\text { te) }\end{array}$ & Nenhum entrevistado \\
\hline
\end{tabular}

Fonte: São Paulo ${ }^{6}$.

parte dos conselheiros. Esse compartilhamento de ações propiciaria o fortalecimento de uma rede intersetorial em torno da concretização do Direito Humano à Alimentação Adequada, o que, entretanto, não é observado.

No segmento governamental, o principal objetivo da maioria das entidades é a prestação de serviços públicos, e as principais atividades são as próprias da função desses órgãos, não sendo possível identificar referência explícita à Segurança Alimentar e Nutricional. Os representantes desse segmento são indicados pelo poder executivo.

Já as entidades da sociedade civil tendem a ter maior afinidade e mais trabalhos rela- cionados ao tema da SAN, assim como seus conselheiros disputam a vaga dentro do segmento a que pertencem. Portanto, de forma geral, estes são mais participativos em reuniões do Conselho do que os representantes governamentais, que parecem demonstrar menor interesse ou mesmo pouca proximidade com a temática, talvez devido à obrigatoriedade de sua indicação.

Apesar da relativa maior participação de conselheiros da sociedade civil, a condução das reuniões, a definição quanto à dinâmica de funcionamento e o poder concentram-se em um ou dois representantes governamentais, conforme encontrado também em outros estudos ${ }^{1,2,8}$. 
O perfil sociodemográfico dos conselheiros do COMUSAN, com relação à escolaridade e renda, não apresenta discrepância entre os dois segmentos (governo e sociedade civil). A maioria dos entrevistados de ambos os segmentos tem curso superior, sendo grande parte em áreas relacionadas a alimentos, meio ambiente e ciências humanas.

Considerando-se o perfil socioeconômico e levando-se em conta os dados do Censo de 2000 para a cidade de São Paulo, verifica-se que os representantes do COMUSAN não são, de forma geral, representativos das classes populares, conforme já indicado em outros estudos que levantaram o perfil sociodemográfico de conseIheiros $^{9-11}$. Enquanto em São Paulo apenas aproximadamente um quarto da população tem renda superior a cinco salários-mínimos, no COMUSAN, 10 entre os 17 conselheiros entrevistados disseram ter renda superior a cinco salários-mínimos ${ }^{(3)}$ e apenas cinco responderam ter renda inferior.

Vale ressaltar que as parcelas populacionais mais vulneráveis à insegurança alimentar e nutricional são as mais excluídas socialmente e também politicamente, não tendo representação específica no COMUSAN ou em outros Conselhos. Desse modo, é importante esclarecer que todas as questões discutidas neste e em outros estudos sobre fóruns participativos são aspectos abordados pela ótica dos 'incluídos', conforme denominam Escorel \& Moreira 3 .

O formato das reuniões é pouco favorável a uma participação efetiva dos conselheiros: as cadeiras são dispostas em fileiras, viradas para frente da sala, de maneira pouco apropriada a uma discussão em grupo. A organização da sala expressa a estrutura das reuniões, em que pautas são desenvolvidas de maneira expositiva, com pouco espaço para participação dos conselheiros, que só podem, por exemplo, apresentar seus informes ao final das reuniões, momento em que parte das pessoas normalmente já foi embora. Durante as reuniões, a maior parte dos conseIheiros quase nunca se expressa, exceto quando é sua vez de apresentar sua entidade ou órgão público, suas atividades, programas ou informes.

A Comissão Executiva que define as pautas das reuniões é dirigida pela presidência do Conselho, formada por representantes da Supervisão Geral de Abastecimento, membros natos do COMUSAN. A presidência apresenta pautas semiprontas para apreciação da Executiva, que pode sugerir pessoas para apresentar temas e outras questões secundárias, mas raramente sugere mudança nas temáticas centrais. É possível perceber a posição dominante do poder executivo municipal na definição das pautas, principalmente pelo enfoque da discussão, sempre orientado para 'como fazer' e menos sobre 'o que fazer' ou sobre as consequências, para a população, do que já foi feito ${ }^{3}$.

O regimento interno do COMUSAN determina que sugestões de temas para a pauta podem ser feitas por qualquer conselheiro; porém, devem ser encaminhadas com antecedência de dez dias para análise da Comissão Executiva, que decide se serão inseridas ou não, sendo que muitas vezes não o são:

No pleno é decidida uma pauta que deve ser levada para o próximo pleno. Só que, a Coordenação Executiva(4) de tirar aquilo que está em pauta, o que na minha concepção é uma coisa errada porque se decidiu no pleno tinha que ser levado em frente. Aí, chega na Coordenação Executiva ela decide que aquele assunto não vai ser mais falado... . Quando (no pleno) se começa a "forçar a barra" consegue cavar um espaço, mas se a entidade não acompanha aquele assunto

3 À época da entrevista (setembro/2009), o valor do salário-mínimo era de R\$465,00. Fonte: <www.dieese.og.br/rel/rac/ salminMenu09-05.xml>.

4 Observa-se que todos os entrevistados referem-se à Comissão Executiva como Coordenação Executiva. No entanto, a primeira denominação é a oficial, encontrada em documentos e atas, enquanto a última é mais correntemente utilizada pelos participantes do COMUSAN. 
que ela quer que seja falado corre o risco de se perder (Representante da sociedade civil, Instituto de pesquisa).

As sugestões de pauta advindas de conselheiros geralmente estavam relacionadas ao orçamento do Conselho e ao financiamento de projetos. Quando essas sugestões foram contempladas, o que ocorreu poucas vezes, de acordo com a análise documental e com o relato dos entrevistados, elas sofreram algum tipo de alteração pela Comissão Executiva.

Os principais meios de divulgação das atas, propostas, ações e decisões do COMUSAN relatados foram: as próprias reuniões, a página eletrônica do Conselho, o Diário Oficial e a publicização pelos próprios conselheiros. Portanto, não há divulgação do Conselho em nenhum meio de comunicação amplamente acessado pela população em geral, o que faz o COMUSAN "invisível" ao público. A pequena visibilidade pública das pautas e decisões dos Conselhos impossibilita que eles funcionem como uma caixa de ressonância das demandas sociais. Dessa forma, o aumento de sua visibilidade por uma parcela maior da sociedade corroboraria para o aumento da democracia no Conselho ${ }^{12}$.

A leitura das atas e as entrevistas com conselheiros demonstram que a temática pautada é dispersa, com predomínio de apresentações de entidades e órgãos públicos, seus temas centrais e ações. Há pouca discussão sobre políticas de SAN.

Os temas de pauta mais citados pelos entrevistados foram: apresentação de projetos (desenvolvidos por subprefeituras, secretarias, entidades da sociedade civil, participantes ou não do Conselho) e apresentação dos diagnósticos das ações de SAN promovidas pelas subprefeituras. Em seguida, aparecem cursos de capacitação para conselheiros e para multiplicadores, e legislação relacionada à SAN. Esse perfil de pautas quase nunca gera discordâncias ou discussões aprofundadas, o que é interpretado por alguns conseIheiros como uma forma de o governo controlar o Conselho e se esquivar de discussões importantes que Ihe causariam desconforto:
Atualmente o COMUSAN tem um desvio de função. O Governo apresenta atividades e parceiros para o pleno conhecer o que vem sendo desenvolvido, quando Ihe interessa (Representante da sociedade civil, Movimento social).

$O$ conselheiro refere-se às constantes apresentações de programas, projetos, órgãos governamentais e parceiros que, de fato, ocupavam espaço significativo nas reuniões do Conselho, conforme constatado em reuniões observadas e leituras das atas.

A falta de seguimento das pautas e o formato de apresentação, que nem sempre contempla tempo para participação dos conselheiros, dificultam a discussão e aprofundamento das temáticas:

Não tem uma coisa que está em pauta e aquilo é discutido em todos os plenos, cada pleno é um momento e ai é esquecido tudo o que se falou antes (Representante da sociedade civil, Instituto de pesquisa)

Segundo a perspectiva da entrevistada, as pautas não são esgotadas, mas citadas superficialmente, sem aprofundamento, não permitindo a resolução de problemas.

Essa situação reflete o pouco domínio do tema e de suas políticas por parte dos conseIheiros, que não as acompanham, não as discutem, não as avaliam nem propõem alternativas.

As principais questões acerca da SAN relacionadas às formas de produção, abastecimento, distribuição e comercialização de alimentos, acesso universal e digno a alimentos de qualidade e culturalmente adequados - não aparecem de forma articulada em discussões, ou não são relatadas como tal nas atas. Quando presentes, aparecem fragmentadas como se fossem temas distintos, e não elementos interligados de um sistema complexo que define a (in)segurança alimentar e nutricional, temática central do Conselho.

A insuficiente discussão desses temas se expressa nas falas de alguns conselheiros que, 
indagados sobre o que entendiam por LOSAN, não sabiam com exatidão do que se tratava, por vezes não respondendo à questão, outras usando discurso vago e genérico sobre SAN e legislação:

É uma norma para se atingir objetivos da SAN. A legislação é um coadjuvante para atuar da melhor maneira, é o respaldo para nossa ação... . O COMUSAN procura buscar o cumprimento da LOSAN através de reuniões para se discutir o tema, esclarecer e reunir as pessoas para atingir os objetivos (Representante governamental, Secretaria de Estado).

Ela que dá a garantia de se cumprir as metas. Centralização das ações e projetos desenvolvidos. Dá mais seriedade a esses projetos que já eram feitos, 'legalizando as ações'. Serve de alanvanco; instigando as pessoas (Representante da sociedade civil, Instituição de ensino privado superior).

Alguns conselheiros confundiam a LOSAN, aprovada nacionalmente em 2006, com uma proposta municipal análoga, elaborada pela gestão anterior do COMUSAN e nunca votada:

É a lei do município criada com o intuito de ajudar a comunidade, criada para estabelecer regras, falar que existe essa lei para tomarmos ciência (Representante governamental, Subprefeitura).

Instrumento essencial para garantir o acesso, o DHAA (Direito Humano à Alimentação Adequada), no município de São Paulo. Foco de garantia de acesso e qualidade (Representante da sociedade civil, Associação patronal).

Sobre essa proposta de LOSAN municipal, importante fruto do trabalho do Conselho para a exigibilidade do DHAA no município, apesar de muito citada, não constava como pauta recorrente do COMUSAN. Além de não constarem discussões a seu respeito nas atas de janeiro de 2008 até junho de 2009, os conselheiros não tinham informação sobre em que instância tramitava a proposta, conforme demonstrado nas falas a seguir:
Pesquisadora: Como o COMUSAN tem atuado com relação à LOSAN?

Conselheiro: Está bem fraco, não está uma relação próxima. Em 2006 o COMUSAN criou a LOSAN municipal. Nos plenos a gente debateu, copiou a LOSAN que a gente tinha e fez para o município. Só que não avançou, eu não sei como foi encaminhado, onde parou isso, onde está. Não tivemos retorno depois disso, eu sei que foi encaminhado, o Conselho encaminhou, mas eu não sei onde está parado esse processo. Mas em relação a pegar o que está na lei, o que está sendo feito ou não, isso aí não tem muita ação não (Representante da sociedade civil, Instituto de pesquisa).

Ajudaram a elaborar a LOSAN municipal, baseada na federal; deram conhecimento sobre a LOSAN para o conselheiro. Porém deixa a desejar a cobrança da realização para o poder público (Representante da sociedade civil, Sindicato de trabalhadores).

Esse é um exemplo da aparente dificuldade do COMUSAN em se posicionar politicamente para fora do seu espaço, em decorrência da forma incipiente e pouco aprofundada como a discussão sobre políticas ocorre internamente. No entanto, o acompanhamento da tramitação de proposta de lei, e mesmo a luta por sua aprovação, seriam atividades esperadas de um Conselho de políticas públicas.

É importante destacar que o município não conta com uma Política de Segurança Alimentar e Nutricional e que a aprovação de uma lei sobre o tema fortaleceria o campo e ofereceria subsídios para a elaboração e implantação de uma política intersetorial com esse objetivo. O que se observa é que, mesmo no Conselho temático, a discussão não está presente, o que se reflete em sua atuação incipiente na proposição de uma política municipal de SAN.

Ainda sobre a LOSAN, aqueles que demonstraram conhecer o conteúdo da lei e discor- 
reram com maior facilidade sobre ela, eram ou tinham sido militantes de sindicatos e movimentos sociais ligados à luta contra a fome e pela garantia da SAN.

Vem para criar condições das diversas ações serem realmente implantadas; e é uma forma da gente cobrar que essas ações sejam realizadas ... uma lei que possibilita essa visão integrada com outras políticas. O principal é ser um instrumento de controle que a gente tem sobre a efetivação dessas ações e políticas (Representante da sociedade civil, Instituto de pesquisa).

A LOSAN tem que orientar as discussões e ações relacionadas ao DHAA nos diversos âmbitos; as diretrizes para o país; cada município pode se basear nela para fazer a sua. Infelizmente não delega ações (Representante governamental, Secretaria Municipal).

As manifestações dos "conselheiros militantes" diferenciaram-se das demais, principalmente com relação à percepção sobre o COMUSAN e suas possibilidades de intervenção nas políticas públicas, a partir da LOSAN, tópico central das entrevistas. Da mesma forma, distiguiram-se seus posicionamentos com relação a diversos assuntos vistos em ata, em diferentes épocas e gestões. Eram quase sempre os que pediam inclusão de pautas, aprofundamento das discussões ou discordavam da Comissão Executiva.

A discrepância entre as falas dos conseIheiros "militantes" e "não militantes" aponta não só o envolvimento político dos primeiros em outros espaços, mas também o papel dessa experiência para sua formação, seu conhecimento sobre o tema e sua habilidade para discutir questões centrais. Como são minoria e, além disso, como sua participação é dificultada pela estrutura e dinâmica de funcionamento do Conselho, eles nem sempre conseguem inserir pautas ou dar seguimento e profundidade às discussões sobre políticas e outros pontos essenciais ligados à SAN. Esses conselheiros, algumas vezes, acabam por se desinteressar da participação no COMUSAN, deixando de frequentar as reuniões, em função do descrédito em relação a esse espaço ou, quando permanecem, envolvem-se em discórdias e conflitos com demais conselheiros e com a Comissão Executiva.

O COMUSAN parece pouco propício à formação política dos conselheiros, seja pelo predomínio de assuntos técnicos e operacionais em relação aos políticos, seja principalmente pelo escasso tempo aberto à participação efetiva dos conselheiros. São registrados poucos momentos de disputas ou divergências de ideias, e quando ocorrem, não costumam ser levados adiante. Além de o próprio espaço não proporcionar essa vivência, os cursos de formação e capacitação realizados geralmente têm caráter técnico (de educação nutricional, palestras sobre doenças) ou objetivam capacitar os conselheiros para o desenvolvimento de tarefas específicas (realização de diagnósticos, elaboração de projetos locais de SAN), e raramente contam com uma abordagem política ou crítica.

Tais características de organização e funcionamento do Conselho, assim como do perfil dos conselheiros, impactam sobre a não atuação do COMUSAN nas políticas públicas de SAN no município de São Paulo. A forma como o Conselho se organiza dificulta a participação ativa de seus participantes, que, de forma geral, apenas de modo incipiente e precário conseguem pautar algumas questões essenciais à construção de políticas de SAN. Devido à despolitização e falta de domínio de muitos conselheiros sobre o tema, e também às dificuldades impostas pela coordenação do Conselho, as discussões sobre essas questões não avançam para análises, avaliações ou propostas de políticas públicas de SAN, fazendo do COMUSAN um Conselho fechado em si mesmo, que não aborda nem reflete os aspectos da realidade sob a qual pretenderia e deveria atuar.

\section{DISCUSS ÃO}

O perfil intelectualizado do COMUSAN parece contribuir para sua atuação distante das 
demandas concretas da população, com discussões pouco polarizadas e pouco politizadas, e em geral com uma atividade muito centrada em informar. A informação ocupa lugar central no Conselho e, junto com a rígida dinâmica organizativa, limita o desenvolvimento de suas reais funções, enquanto instância de participação e controle social de políticas públicas.

A SAN é uma temática complexa, intersetorial e pouco conhecida, restrita ao meio acadêmico e timidamente presente nos movimentos sociais. A problemática não é percebida pela maior parte da população como um direito (a todos se alimentarem de maneira adequada e saudável) e nem como uma demanda imediata, como ocorre com a saúde, por exemplo.

O isolamento político do COMUSAN pode também ser um fator que explique sua atuação política quase invisível. Não há mobilização social que impacte sobre o Conselho, nem movimento que o pressione nem tampouco lhe exija ações. Além disso, é importante salientar que o Conselho Estadual de Segurança Alimentar e Nutricional de São Paulo(5) é o único do país que não funciona regularmente ${ }^{13}$, o que pode influenciar também a atuação do COMUSAN, que atua sem referência e sem interlocução com o nível estadual.

A pouca visibilidade do tema de SAN na sociedade em geral, assim como entre os movimentos políticos e sociais, contribui para que o Conselho fique sem base social consolidada que demande e pressione por ações e políticas, ficando a mercê de outros interesses. E, apesar dos esforços de algumas entidades da sociedade civil, a pauta continua ocupando posição secundária na arena política municipal, tanto nas instâncias governamentais quanto na sociedade como um todo.

Essa desmobilização política em torno do tema, ao mesmo tempo em que se reflete no COMUSAN, pode também ser influenciada por ele, visto que seria também uma desejável ativi- dade do Conselho a divulgação e publicização do tema, bem como de suas ações, junto a outros espaços, objetivando, por exemplo, a inserção de novos atores e a formação de redes em torno da SAN.

Por ser uma temática essencialmente intersetorial, a Segurança Alimentar e Nutricional poderia encontrar na formação de redes sociais uma importante estratégia para a organização de sua luta. Segundo Stotz ${ }^{14}$, "a apropriação crítica do conceito de redes sociais como elemento compreensivo da dinâmica social em suas possibilidades e limites possibilita explorar a riqueza de experiências de ação e solidariedade". O autor defende que essas experiências apontam para a mudança social, partindo de caminhos mais democráticos que tendem a revalorizar processos de construção de consenso por meio da democracia representativa.

No caso da SAN, a organização em redes e a consequente formação de consenso de pautas entre os grupos dos diferentes setores - desde movimentos pela reforma agrária até movimentos pela regulamentação da propaganda de alimentos - poderiam otimizar suas lutas, aumentando chances de conquistas comuns.

Em estudo junto às entidades da sociedade civil participantes do CONSEA Nacional, Costa ${ }^{15}$ constatou o papel articulador do Fórum Brasileiro de Segurança Alimentar e Nutricional (FBSAN) Atualmente denominado de Fórum Brasileiro de Soberania e Segurança Alimentar e Nutricional -, e sua importância para o bom desempenho desse Conselho. Além da proposição de políticas, o FBSAN tem investido em ações de mobilização da sociedade civil e na construção de propostas intersetoriais, a partir da interlocução com outras redes. Em seu estudo, Costa ${ }^{15}$ mostrar como, a partir dessa atuação, redes de diferentes campos, unidas em torno de objetivos em comum, têm conseguido avanços na questão do DHAA.

Apesar das evidentes diferenças de poder, articulação e mobilização entre Conselhos de

\footnotetext{
$\overline{\mathbf{5}} \mathrm{O}$ referido Conselho não publiciza suas reuniões nem participa dos espaços de discussão promovidos periodicamente pelo CONSEA nacional.
} 
diferentes instâncias (nacional, estadual e municipal), o que se pretende com o exemplo do CONSEA e do FBSAN é apontar a importância de entidades e/ou movimentos autônomos e consolidados nas bases sociais, que tenham inserção em espaços diversos. Principalmente, quer-se apontar a necessidade de se articularem em redes os diferentes movimentos, a fim de ampliar sua visibilidade, força e potencial de ação.

Nesse sentido, a atuação em redes poderia aproximar a temática da Segurança Alimentar e Nutricional de discussões concretas da sociedade, como: qualidade da alimentação escolar e sua compreensão enquanto um direito; preço de alimentos saudáveis e sua relação com a saúde da população; produção de alimentos biologicamente mais seguros; permanência do homem no campo; justiça social no campo e nas cidades, entre outras questões cotidianas ainda invisíveis para grande parte das pessoas.

Para tanto, acredita-se ser um caminho a participação, no COMUSAN, de movimentos sociais e de organizações populares não governamentais, com bases sociais e inserção na sociedade. Assim, o Conselho, na condição de fórum participativo, cumpriria sua função de inserir a população, historicamente excluída da vida política do país, em espaços de decisão e poder.

Além da organização da sociedade civil, é importante advertir que o funcionamento "bom", "regular" ou "ruim" de Conselhos participativos depende também, em grande parte, da atuação e postura do poder público da esfera em que se encontra ${ }^{16}$. No caso específico do município, diversos estudos ${ }^{16}$ apontam como principal característica da participação em São Paulo seu aspecto de "sanfona", que se expande e se contrai de acordo com as ações do poder público, ou seja, em decorrência das políticas participativas definidas pelo Estado e dirigidas às associações civis ${ }^{8}$.

Em trabalho analisando estudos com diferentes Conselhos gestores de políticas públicas, assim como no COMUSAN, é relatada limitada representatividade dos conselheiros governamentais. Devido ao frágil vínculo com seus órgãos de origem, esses conselheiros tendem a defender suas opiniões particulares e não o posicionamento dos órgãos que representam, mesmo porque as questões dos Conselhos não costumam ser discutidas nesses órgãos. Algumas vezes, os Conselhos sequer conhecem a posição do governo sobre os assuntos discutidos. A fraca interlocução entre Conselhos e agências estatais produz o esvaziamento e o consequente enfraquecimento dessas instâncias, que, apesar de suas prerrogativas legais, não conseguem, de fato, participar de decisões importantes, que acabam acontecendo no interior de gabinetes dos altos escalões do governo, sob influência de seus tradicionais interlocutores'.

Também no campo das representações não governamentais, observa-se o frágil vínculo entre conselheiros e entidades ou movimentos sociais. Nesse caso, o problema da falta de um debate prévio entre representantes e entidades é que, não tendo posição discutida e amadurecida, o segmento, por vezes, acaba aderindo às posições defendidas por grupos com maior poder de argumentação e influência, as quais podem não refletir os interesses do grupo que ele representa.

Os conselheiros denominados de "militantes" neste estudo têm uma atuação relacionada a vivências, habilidades e conhecimentos desenvolvidos a partir de experiências concretas. Demonstram maior formação política, possivelmente adquirida em outros espaços de participação política, como outros Conselhos, associações populares, sindicatos e movimentos sociais. Esses "experimentos participativos" desempenham um papel educativo na formação de seus participantes, pois não apenas Ihes fornece informações, mas também os capacita para a tomada de decisão e desenvolve sabedoria política, assim contribuindo para o desenvolvimento político dos indivíduos ${ }^{17}$. A atuação destoante e mais qualificada politicamente dos "conselheiros militantes" é um reflexo do caráter pedagógico da participação em Conselhos e em outras instâncias participativas, e expressa o potencial 
desses espaços em promover, por meio do exercício de cidadania, o aprimoramento do sentido público de quem participa, além de conferir um novo significado à política. Essa parece ser uma forma interessante e inovadora de possibilitar que tais indivíduos exerçam um papel na gestão pública ${ }^{3}$.

Porém, na prática, a pedagogia da cidadania é substituída pela capacitação dos conseIheiros em questões técnicas, o que desqualifica sua representação política, seu verdadeiro papel. Essa distorção não aprimora nem a cidadania do representante, nem a instância democrática ${ }^{3}$.

Processos educativos politicamente comprometidos com a capacitação de indivíduos para sua autonomia e emancipação devem ter como referencial teorias pedagógicas críticas, que vinculam o projeto educativo à comunidade na qual ele se insere, de modo a possibilitar a mudança individual e social ${ }^{18}$. No caso de Conselhos de SAN, as capacitações pontuais devem se configurar como "processos formativos" vinculados à realidade de cada localidade e às experiências práticas que promovam a autonomia e o empoderamento. Tais capacitações devem, ainda, considerar as múltiplas dimensões da SAN, indo para além do campo específico da educação nutricional, por meio do exercício da interdisciplinaridade como elemento constitutivo de uma nova maneira de se pensarem os alimentos e a alimentação ${ }^{15}$.

É possível que se imagine que, dependendo da importância dada pelo Estado aos fóruns participativos, se esses Conselhos se tornassem realmente lócus de poder em que decisões importantes fossem tomadas e concretizadas, as disputas internas se acirrariam, as discussões se enriqueceriam e tanto sociedade civil como governo teriam maior preocupação e responsabilidade com o espaço e ele poderia, de fato, influenciar políticas públicas. Essas considerações são importantes para esclarecer que as incipientes reflexões sobre a participação política do COMUSAN, presentes neste artigo, enfatizam a necessidade de politização e participação da sociedade civil. Mas não objetivam, de forma alguma, minimizar a problemática da burocratização e hierarquia de poder que impede transformações substantivas na formulação de políticas públicas de SAN. Muito menos, pretendem canalizar para o COMUSAN uma responsabilidade, reconhecidamente do Executivo e Legislativo, de elaborar e implantar políticas públicas que garantam a Segurança Alimentar e Nutricional para toda a população.

\section{CONCLUS Ã O}

A forma como o COMUSAN se estrutura e funciona internamente, de maneira rígida, burocratizada e pouco permeável à participação ativa dos conselheiros, assim como o perfil despolitizado destes e a atuação distante da realidade, fazem com que esse órgão não acompanhe de maneira crítica as ações e programas de SAN desenvolvidas no município. Assim, o Conselho deixa de analisar, monitorar, avaliar, propor ou deliberar sobre tais ações, não contribuindo para a construção de uma política pública de SAN no município. Trata-se de um círculo vicioso em que nem o Conselho atinge a "realidade", nem esta chega até ele.

O perfil dos conselheiros e a organização do Conselho, além da complexidade do tema e sua pequena inserção na sociedade, fazem com que o órgão conte com poucos representantes das classes populares. Estes, por outro lado, poderiam trazer demandas concretas, seja por representarem a maior parte da população em situação de insegurança alimentar e nutricional (mesmo considerada em sua amplitude), seja por representarem movimentos sociais que concentram demandas populares. Supõe-se que esses grupos sociais poderiam fomentar um debate mais pautado na realidade material da população, mais politizado e mais apto a contribuir para a construção de uma Política de Segurança Alimentar e Nutricional efetiva no município de São Paulo.

Também a concentração de poder presente no funcionamento do COMUSAN, sua dinâmica 
pouco participativa e sua atuação despolitizada fazem-no quase invisível e pouco eficaz tanto no acompanhamento como na formulação de políticas de SAN para o município. Algumas ações poderiam ser realizadas no sentido de torná-lo mais eficaz, democrático e aberto à entrada de novos atores sociais, como: flexibilizar a dinâmica das reuniões, com maior abertura para a participação dos conselheiros e para a inserção de pautas e discussões sobre políticas; promover a formação política de conselheiros e movimentos sociais afetos ao tema; divulgar a temática em diferentes espaços do governo e da sociedade; divulgar o papel do Conselho, seus objetivos e resoluções; fortalecer a interlocução com grupos sociais de diferentes setores relacionados à SAN, para a formação de redes sociais consolidadas em torno do tema, que atuem com mais força pela garantia do Direito Humano à Alimentação Adequada a todas as pessoas.

\section{A GRADECIMENTOS}

Aos conselheiros do COMUSAN de São Paulo que participaram desta pesquisa.

\section{OLABORADORES}

NC ROCHA contribuiu com a concepção, desenho, análise e interpretação dos dados do artigo. CM BÓGUS contribuiu com a concepção e desenho do artigo. NG DORIA e JM BOIA contribuíram com a análise e interpretação dos dados do artigo.

\section{REFER Ê N CIAS}

1. Tatagiba L. Os conselhos gestores e a democratização das políticas públicas no Brasil. In: Dagnino E, organizador. Sociedade civil e espaços públicos no Brasil. São Paulo: Paz e Terra; 2002.

2. Wendhausen A, Caponi S. O diálogo e a participação em um conselho de saúde em Santa Catarina, Brasil. Cad Saúde Pública [Internet]. 2002 [acesso 2010 nov 7]; 18(6):1621-28. Disponível em: <http://www.scielo.br>. doi: 10.1590/S0102$311 \times 2002000600016$.

3. Escorel S, Moreira MR. Desafios da participação social em saúde e na nova agenda da reforma sanitária: democracia deliberativa e efetividade. In: Fleury S, Lobato LVC. Participação, democracia e saúde. Rio de Janeiro: Cebes; 2009.

4. Labra ME. Conselhos de saúde: dilemas, avanços e desafios. In: Lima NT, Gerschman S, Edler FC, Suárez JM, organizadores. Saúde e democracia: história e perspectivas do SUS. Rio de Janeiro: Fiocruz; 2006.

5. Vasconcelos FAG. Combate á fome no Brasil: uma análise histórica de Vargas a Lula. Rev Nutr [Internet]. 2005 [acesso 2010 ago 14]; 18(4):439-57. Disponível em: <http://mww.scielo.br/rn>. doi: 10.1590/s1 415-52732005000400001.

6. Brasil. Lei $n^{\circ} 11346$, de 15 de setembro de 2006. Cria o Sistema Nacional de Segurança Alimentar e Nutricional - SISAN com vistas em assegurar o direito humano à alimentação adequada e dá outras providências [Internet]. Brasília; 2006 [acesso 2009 ago 16]. Disponível em: <http://www.mds. gov.br>.

7. São Paulo. Prefeitura Municipal de São Paulo [Internet]. Decreto $n^{\circ}$ 50.126, de 17 de outubro de 2008. Confere nova disciplina ao Conselho Municipal de Segurança Alimentar e Nutricional COMUSAN-SP e revoga o Decreto $n^{\circ} 42.862$, de 13 de fevereiro de 2003 [Internet].São Paulo: Secretaria do Governo Municipal; 2008 [acesso 2009 ago 7]. Disponível em: <http://www3. prefeitura.sp.gov.br>.

8. Bógus CM. Conselhos gestores de políticas públicas no município de São Paulo: identidade, limitações e potencialidades na perspectiva da Promoção da Saúde [livre-docência]. São Paulo: Universidade de São Paulo; 2009.

9. Abers RN, Keck ME. Representando a diversidade: estado, sociedade e "relações fecundas" nos conselhos gestores. Cad CRH [Internet]. 2008 [acesso 2010 ago 20]; 21(52):99-112. Disponível em: <http://www.scielo.br>. doi: 10.1590/S0103-49 792008000100008.

10. Fuks M, Perissinotto RM, Ribeiro EA. Cultura política e desigualdade: o caso dos Conselhos Municipais de Curitiba. Rev Sociol Polit [Internet]. 2003 [acesso 2010 ago 14]; 21:125-45. Disponível em: <http://www.scielo.br>.doi: 10.1590/S0104-44 782003000200009.

11. Wendhausen ALP, Barbosa TM, Borba MC. Empoderamento e recursos para a participação em conselhos gestores. Rev Saúde Soc [Internet]. 2006 
[acesso 2010 set 2]; 15(3):131-44. Disponível em: <http://www.scielo.br>. doi: 10.1590/S0104-1290 2006000300011.

12. Pitta AMR. Comunicação em saúde: a complexidade dos conceitos e os desafios das práticas. In: Informação e comunicação social em saúde. ília: OPAS; 1996. Série Desenvolvimento de Serviços de Saúde 15.

13. Conselho Nacional de Segurança Alimentar e Nutricional [Internet]. Conselhos estaduais: situação de funcionamento dos Conseas estaduais 2010. [acesso 2010 out 26]. Disponível em: <http://www. planalto.gov.br/consea/exec/index.cfm>.

14. Stotz EN. Redes sociais e saúde. In: Marteleto RM, Stotz EM, organizadores. Informação, saúde e redes sociais: diálogos de conhecimento nas comunidades da Maré. Rio de Janeiro: Fiocruz; 2009. Parte I.
15. Costa CGA. Segurança alimentar e nutricional: significados e apropriações. São Paulo: Fapesp; 2011.

16. Avritzer L, Recamán M, Venturi G. O Associativismo em São Paulo. In: Avritzer L, organizador. A participação em São Paulo. São Paulo: Unesp; 2004.

17. Gohn MG. Conselhos gestores e participação sociopolítica. $2^{a}$ ed. São Paulo: Cortez; 2003.

18. Ayuste A, Flecha R, López Palma F, Lleras J. Planteamientos de la pedagogía crítica: comunicar y transformar. Barcelona: Graó Editorial; 1994.

Recebido em: 18/11/2010

Versão final reapresentada em: 9/11/2011

Aprovado em: 9/1/2012 